\title{
Solid-Liquid Extraction with Low Temperature Purification Coupled with Gas Chromatography and Mass Spectrometry for Determination of Polychlorinated Biphenyls in Sewage Sludge
}

\author{
Mariana R. Maia, Ana Luiza P. Arcanjo, Gevany P. Pinho* and Flaviano O. Silvério \\ Instituto de Ciências Agrárias, Universidade Federal de Minas Gerais, \\ Avenida Universitária, 1000, 39404-547 Montes Claros-MG, Brazil
}

\begin{abstract}
Sewage sludge is the residue produced by the wastewater treatment plants, which can be used as soil conditioner in agriculture. However, the current legislation recommends monitoring chemical contaminants such as polychlorinated biphenyls (PCBs). In this study, solid-liquid extraction with low temperature purification (SLE-LTP) was optimized and validated for monitoring six PCBs. The analyses were performed by gas chromatography and mass spectrometry. Sulfur interference was removed by $1.5 \mathrm{~g}$ of copper metal. The extraction was carried out using $6.50 \mathrm{~mL}$ isopropanol, $1.50 \mathrm{~mL}$ ethyl acetate, $0.1 \mathrm{~g} \mathrm{NaCl}, 0.8 \mathrm{~mL}$ water and $15 \mathrm{~min}$ into ultrasound. Extraction percentages were between 82 and $94 \%$ and relative standard deviation $\leq 16 \%$ for low concentrations. Detection and quantification limits were 3.3 and $10 \mu \mathrm{g} \mathrm{kg}^{-1}$, respectively. The method was applied to sludge samples collected monthly in the wastewater treatment plant and PCB 52 was detected in six samples.
\end{abstract}

Keywords: PCB, sewage sludge, SLE-LTP, extraction method

\section{Introduction}

Sewage sludge is the solid residue produced by the wastewater treatment plants (WWTP). This residue can be used in agriculture as a fertilizer complement or soil conditioner. The sludge has a high content of organic matter and essential elements to plants such as nitrogen and phosphorus. ${ }^{1,2}$

However, sewage sludge may contain chemical contaminants which can be transferred to soil, plants, animals, rivers and groundwater. ${ }^{3-6}$ Among the contaminants, polychlorinated biphenyls (PCBs) stand out for being highly persistent in soil, for their low biodegradability and high lipophilicity and the proven harmful effects on biota and carcinogenicity on humans. ${ }^{7-10}$ Although these compounds have been banned by the 2001 Stockholm Convention, recently, 209 polychlorinated biphenyl congeners have been identified in sewage effluents. ${ }^{11}$ The PCB congeners named $28,52,101,138,153$ and 180 are known as indicators of environmental pollution due to their highly frequent detection in environmental and biological samples. ${ }^{12-14}$

PCBs are quantified by gas chromatography and mass spectrometric detection (GC-MS) or electron capture

*e-mail: gevanypp@ufmg.br detection (ECD). ${ }^{15}$ Traditional techniques such as shaker table, ${ }^{16}$ soxhlet extraction ${ }^{17}$ and ultrasound ${ }^{18}$ are the most used ones for PCB studies on sewage sludge. ${ }^{19}$ Accelerated solvent extraction, a more sophisticated technique, has also been used. ${ }^{20}$

Recently, solid-liquid extraction with low temperature purification (SLE-LTP) was used for quantification of polycyclic aromatic hydrocarbons (PAHs) and chlorobenzenes in sewage sludge. ${ }^{21,22}$ The principle of the technique was proposed by McCulley and McKinley in 1964, ${ }^{23}$ but only in 2007 the technique was modified for pyrethroid determination in water, which was initially named liquid-liquid extraction with lowtemperature partition (LLE-LTP). ${ }^{24}$ Significant advances in this technique have been achieved for the monitoring of chemical contaminants and, in the last eight years, it has been optimized and validated for different matrices such as milk, ${ }^{25}$ tomato, ${ }^{26}$ human urine, ${ }^{27}$ beverages,${ }^{28}$ human liver, ${ }^{29}$ pineapple,,$^{30}$ lettuce ${ }^{31}$ and Caiman yacare eggs. ${ }^{32}$

The principle of SLE-LTP is based on the addition of a homogenous mixture composed of water and organic solvent to the sample. The system is homogenized and cooled to $-20{ }^{\circ} \mathrm{C}$ to freeze the matrix components and the aqueous phase. The organic phase, typically acetonitrile, remains liquid and extracts the compounds of interest. The 
technique enables extraction and cleaning of extracts in one step, but depending on the matrix complexity, the extract may be subjected to solid phase extraction (SPE) prior to chromatographic analysis. ${ }^{33}$

This study aimed to optimize and validate SLE-LTP of six polychlorinated biphenyls in sewage sludge samples. Extracts were analyzed by gas chromatography-mass spectrometry (GC-MS). The validated method was applied to analyze sludge samples from the WWTP of Montes Claros City, Brazil, from May to November 2013.

\section{Experimental}

\section{Materials}

PCBs 28, 52, 101, 138, 153 and 180, analytical standard, were purchased from Sigma-Aldrich (St. Louis, USA). The high performance liquid chromatography (HPLC) grade solvents hexane, acetonitrile, ethyl acetate and acetone were purchased from Vetec (Rio de Janeiro, Brazil). Isopropanol was purchased from Carlo Erba (France). Reagents anhydrous sodium sulfate and sodium chloride of purity greater than $99 \%$ were purchased from Vetec (Rio de Janeiro, Brazil). Copper metal of $99 \%$ purity was purchased from Neon (São Paulo, Brazil). Silica gel 230-400 mesh was purchased from Carvalhaes (Germany).

\section{Equipment and chromatographic analysis}

The equipment included a vortex (Phoenix, Brazil), an agitation bath (Solab, Brazil), a centrifuge (Kindly, Brazil), a vacuum pump (New, USA), an ultrasonic bath (Unique, Brazil) and a Visiprep (Supelco, Brazil).

The chromatographic analysis was performed in a 7890A gas chromatograph coupled to 5975C mass spectrometer (Agilent Technologies) using a DB5-MS capillary column (Agilent Technologies), stationary phase 5\% phenyl and 95\% methylsiloxane, $(30 \mathrm{~m}$ length $\times 0.32 \mathrm{~mm}$ internal diameter $\times 0.25 \mu \mathrm{m}$ film), helium ( $99.9999 \%$ purity) as carrier gas at $1.5 \mathrm{~mL} \mathrm{~min}^{-1}$ flow rate. The split/splitless injector was held at $280{ }^{\circ} \mathrm{C}$. The temperature program was $70{ }^{\circ} \mathrm{C}, 12^{\circ} \mathrm{C} \mathrm{min}^{-1}$ to $140{ }^{\circ} \mathrm{C}, 25{ }^{\circ} \mathrm{C} \min ^{-1}$ to $190{ }^{\circ} \mathrm{C}, 7{ }^{\circ} \mathrm{C} \min ^{-1}$ to $280{ }^{\circ} \mathrm{C}$. The injection volume was $1 \mu \mathrm{L}$ in the split ratio 1:5, using a CombiPAL injector. The mass detector was operated in the electron impact mode $(70 \mathrm{eV})$ and a quadrupole mass analyzer. The interface was kept at $280{ }^{\circ} \mathrm{C}$ and the ion source at $230{ }^{\circ} \mathrm{C}$. Device control and data acquisition were carried out using the ChemStation software (E.02.02.1431 copyright $^{\oplus}$ 1989-2011- Agilent Technology).

Analyses were performed in selective ion monitoring mode (SIM) and data acquisition was divided into five groups of ions. Group 1 ( 0 to $11.50 \mathrm{~min}$ ) comprised ions 186, 256, $292 \mathrm{~m} / z$; group 2 (11.51 to $13 \mathrm{~min}$ ) ions $150,207,255 \mathrm{~m} / z$; group 3 (13.01 to $14.50 \mathrm{~min}$ ) ions $256,324,326 \mathrm{~m} / z$; group 4 (14.51 to $16.20 \mathrm{~min}$ ) ions $290,360,362 \mathrm{~m} / z$; and group 5 (16.21 to $18 \mathrm{~min}$ ) ions $324,394,396 \mathrm{~m} / \mathrm{z}$.

\section{Standard solutions}

Standard stock solutions from the six congeners were prepared separately in hexane in the concentration of $400 \mathrm{mg} \mathrm{L}^{-1}$ and stored at $-20^{\circ} \mathrm{C}$. The working solutions were then prepared from the dilution of the stock solutions in the same solvent, containing all the six congeners in the concentration of $20 \mathrm{mg} \mathrm{L}^{-1}$.

\section{Sewage sludge samples}

Biphenyl-free sludge samples were collected from the drying bed of the wastewater treatment plant of the municipality of Juramento City, Minas Gerais, Brazil. These samples were used during the steps of SLE-LTP optimization and validation. The moisture content was determined by weighing $2.0000 \mathrm{~g}$ of sample in five replicates. Samples were placed in an oven at $100{ }^{\circ} \mathrm{C}$ and were weighed every hour until constant weight.

The sludge samples were collected in the wastewater treatment plant in the municipality of Montes Claros-MG, from May to November 2013 for application of the method in real samples.

\section{SLE-LTP}

The parameters copper mass, extraction solvent composition, form and time of homogenization, change in ionic strength, water $\mathrm{pH}$ and elution solvent volume were optimized in the SLE-LTP (Table 1). Extraction percentages in each optimization condition were analyzed by the $t$-test $(p<0.05)$.

In the optimized method, $4.0000 \mathrm{~g}$ of sludge were added to $22-\mathrm{mL}$ glass flask and after spiked with $100 \mu \mathrm{L}$ of standard solution $\left(62.5 \mu \mathrm{g} \mathrm{kg}^{-1}\right)$. The system was maintained at rest for $3 \mathrm{~h}$. In the sample was added $0.80 \mathrm{~mL}$ of an aqueous solution containing $0.1 \mathrm{~g} \mathrm{NaCl}$. To the flask was added $6.50 \mathrm{~mL}$ isopropanol, $1.50 \mathrm{~mL}$ ethyl acetate and $1.5000 \mathrm{~g}$ copper metal. The system was homogenized in ultrasonic bath for $15 \mathrm{~min}$ and incubated in a stirring water bath at $40^{\circ} \mathrm{C}$ for one hour. The samples were then kept at $-20^{\circ} \mathrm{C}$ for two hours. The extracts were subjected to an additional clean up step in the manifold with flow rate of $1 \mathrm{~mL} \mathrm{~min}^{-1}$. The cartridge was prepared with $2.0 \mathrm{~g}$ silica and $1.5 \mathrm{~g}$ sodium sulfate. The extract was 
Table 1. Parameters evaluated in the SLE-LTP of six PCBs in sewage sludge samples

\begin{tabular}{lc}
\hline Parameter & Level \\
\hline Metallic copper / $\mathrm{g}$ & $0.5,1.0,1.5$ and 2.0 \\
Extraction mixture / $\mathrm{mL}$ & 6.50 acetonitrile / 1.50 ethyl acetate \\
7.50 isopropanol / 0.50 hexane & 6.50 isopropanol / 1.50 ethyl acetate \\
& 7.50 isopropanol / 0.50 ethyl acetate \\
& 6.50 acetone / 1.50 hexane \\
Homogenization / min & vortex for 1 and 5 \\
ultrasound for 15 and 30 \\
Water pH \\
Elution volume / $\mathrm{mL}$
\end{tabular}

eluted with isopropanol and collected into a $10.00 \mathrm{~mL}$ volumetric flask.

\section{Validation}

Selectivity, linearity, limit of detection (LOD), limit of quantification (LOQ), accuracy and precision were evaluated. ${ }^{34}$ Linearity was evaluated by preparing the calibration curve with seven concentration levels. The concentrations 4, 10, 20, 30, 40, 50 and $60 \mu \mathrm{g} \mathrm{L}^{-1}$ were used with three independent replicates for each level. The least square linear regression was applied to the experimental data for estimating the regression parameters. The outliers were treated and confirmed by the Jacknife test with maximum exclusion of $22.2 \%$ of the data. Regression analysis was evaluated by the parameters normality (Ryan and Joiner test), homoscedasticity (Brown and Forsythe test) and independence (Durbin and Watson test). Analysis of variance (ANOVA) was applied to each solvent and matrix calibration curve to test the lack of fit of linearity. The matrix effect was assessed by calculating the percentage of variation of the chromatographic response $\left[\%=\left(\overline{\mathrm{A}}_{\text {matrix }}-\overline{\mathrm{A}}_{\text {solvent }}\right) / \overline{\mathrm{A}}_{\text {solvent }} \times 100\right]$. The means of areas obtained for each PCB in solvent and matrix were compared by the $t$-test.

The selectivity of the method was investigated by evaluating the PCB-free samples (blank) in six independent replicates. Other interferences such as solvent derivatives, glassware, adsorbents and reagents were investigated by reapplying the method without using sewage sludge samples.

Limits of detection (LOD) and limits of quantification (LOQ) were determined by fortifying the sludge samples with biphenyls in the lowest acceptable concentrations. LOD and LOQ were considered as three and ten times, respectively, the baseline noise signal obtained for the samples free of biphenyls (blank).

Accuracy was evaluated by fortification/recovery experiments. Three concentration levels were studied 4, 8 and $20 \mu \mathrm{g} \mathrm{L}^{-1}$ in three replicates. Recovery values for each level were considered acceptable when between 70 and $120 \%$. $^{34}$

Precision, under repeatability conditions, was evaluated by the relative standard deviation (RSD) obtained from fortification/recovery experiments of biphenyls in sludge. The tests were performed in the concentration of $8 \mu \mathrm{g} \mathrm{L}^{-1}$ in seven replicates. The acceptability criterion for RSD was $\leq 20 \% .^{34}$

\section{Results and Discussion}

\section{SLE-LTP optimization}

Previous studies have shown that the optimum ratio of organic solvent-water mixture in SLE-LTP is 8 to $4 \mathrm{~mL} \cdot{ }^{24,26}$ In this study, the sludge samples contained $80 \%$ water $(\mathrm{m} / \mathrm{m})$. Thus, $0.8 \mathrm{~mL}$ of water was added to $4 \mathrm{~g}$ of sludge, resulting in $4 \mathrm{~mL}$ of water.

The first SLE-LTP parameter optimized was the addition of copper metal to the sludge sample. Copper removes sulfur compounds that interfere with the chromatographic analysis. ${ }^{35,36}$ Thus, different masses of powdered copper were added to the sludge. Addition of $1.5 \mathrm{~g}$ of copper removed interferents in the same retention time of the biphenyls and four intense signals named A, B, $\mathrm{C}$ and $\mathrm{D}$ (Figure 1). Therefore, this mass was used in the other optimization steps.

Although acetonitrile is traditionally used in SLE-LTP as extraction solvent, ${ }^{25}$ four less polar extractor mixtures were assessed for the recovery of biphenyls (Table 2). The mixture isopropanol:ethyl acetate in the ratio 6.50:1.50 $\mathrm{mL}(\mathrm{v} / \mathrm{v})$ had the highest recovery rates for the six biphenyls, with values greater than $50 \%$, as compared by the $t$-test $(p<0.05)$.

To improve the percentage recovery of biphenyls, the system homogenization was tested using vortex and ultrasound in two different times (Table 2). The results showed that homogenization in ultrasound for $15 \mathrm{~min}$ had higher percentage recovery for four biphenyls, as compared by the $t$-test $(p>0.05)$.

Previous studies have reported the salting out effect during the extraction of contaminants in environmental matrices using SLE-LTP or LLE-LTP. ${ }^{21,37,38}$ Aliquots of $0.80 \mathrm{~mL}$ water containing $0,0.1$ and $0.2 \mathrm{~g} \mathrm{NaCl}$ were 


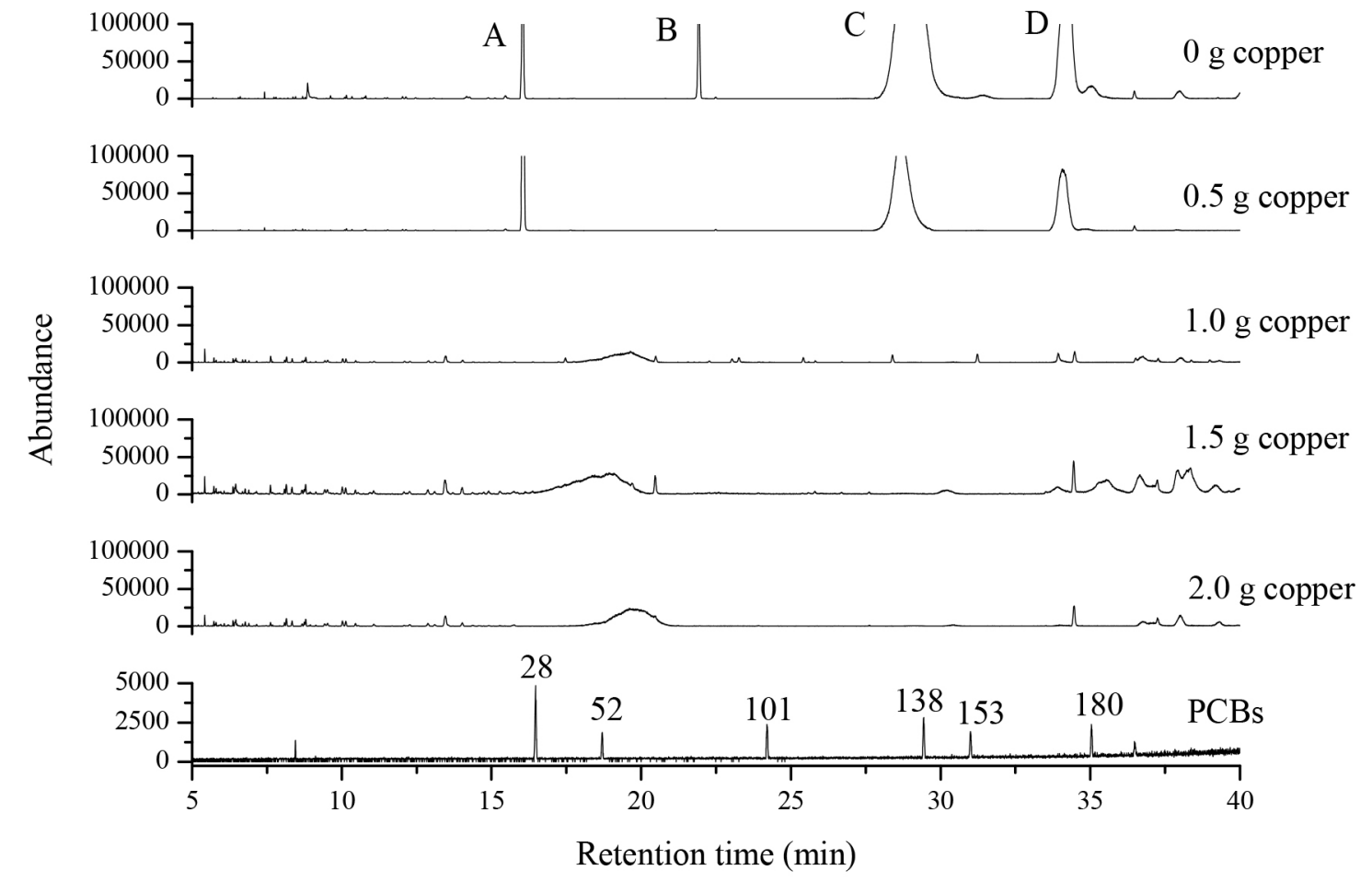

Figure 1. Total ion chromatograms of sludge extracts obtained by SLE-LTP using 0, 0.5, 1.0, 1.5 and $2.0 \mathrm{~g}$ of metallic copper. In addition, standard solution containing the PCBs in acetonitrile at $500 \mu \mathrm{g} \mathrm{L}^{-1}$.

added to the sludge samples during SLE-LTP. Higher amounts of $\mathrm{NaCl}$ promoted the separation of the organic and aqueous phases before the temperature lowering and hence they were not used. The higher recovery percentages were obtained with the addition of $0.1 \mathrm{~g} \mathrm{NaCl}(p<0.05)$ (Table 2). This positive effect is associated with ion solvation by water molecules, facilitating the migration of PCBs into the organic phase.

Although the chemical structure of the biphenyls does not change under $\mathrm{pH}$ variation, the sludge matrix components can ionize or degrade, influencing biphenyl extraction. The $\mathrm{pH}$ of the water added to the sludge sample was adjusted to 3,7 and 13 . The highest recovery percentages were obtained at $\mathrm{pH} 7$ for the six biphenyls (Table 2), as compared by the $t$-test $(p<0.05)$. Similar results were reported using SLE-LTP for extraction of pesticides in honey. ${ }^{33}$

After the sample freezing in SLE-LTP, the volume of the organic phase reduced from 8 to about $5 \mathrm{~mL}$, because part of the organic solvent was retained in the solidified phase. These $5 \mathrm{~mL}$ extracts were subjected to the additional step of cleaning with silica to remove remaining interferents. The isopropanol volume added as eluent changed the recovery percentages of the biphenyls (Table 2). The highest recovery percentages were obtained with a final volume of $10 \mathrm{~mL}$ extract $(p<0.05)$. Although the addition of the highest volume of isopropanol had diluted the extract, there was

Table 2. Recovery percentage \pm RSD of PCBs in sewage sludge samples during optimization of the SLE-LTP

\begin{tabular}{|c|c|c|c|c|c|c|c|c|c|c|c|c|c|c|c|c|}
\hline \multirow{3}{*}{ Compound } & \multicolumn{4}{|c|}{ Mixture extraction } & \multicolumn{4}{|c|}{ Homogenization } & \multicolumn{3}{|c|}{ Ionic strength / g } & \multicolumn{3}{|c|}{$\mathrm{pH}$} & \multicolumn{2}{|c|}{ Elution / mL } \\
\hline & \multirow{2}{*}{$\begin{array}{c}\text { ACN:ETA } \\
(6.5: 1.5)\end{array}$} & \multirow{2}{*}{$\begin{array}{c}\text { ISO:HEX } \\
(7.5: 0.5)\end{array}$} & \multirow{2}{*}{$\begin{array}{c}\text { ISO:ETA } \\
(6.5: 1.5)\end{array}$} & \multirow{2}{*}{$\begin{array}{c}\text { ISO:ETA } \\
(6.0: 2.0)\end{array}$} & \multicolumn{2}{|c|}{ Vortex } & \multicolumn{2}{|c|}{ Ultrasound } & \multirow{2}{*}{0} & \multirow{2}{*}{0.1} & \multirow{2}{*}{0.2} & \multirow{2}{*}{3} & \multirow{2}{*}{7} & \multirow{2}{*}{13} & \multirow{2}{*}{5} & \multirow{2}{*}{10} \\
\hline & & & & & $1 \mathrm{~min}$ & $5 \mathrm{~min}$ & $15 \mathrm{~min}$ & $30 \mathrm{~min}$ & & & & & & & & \\
\hline PCB 28 & $44 \pm 7$ & $43 \pm 8$ & $58^{\mathrm{a}} \pm 2$ & $38 \pm 4$ & $58 \pm 2$ & $73 \pm 11$ & $57^{a} \pm 2$ & $49 \pm 3$ & $57 \pm 2$ & $73^{a} \pm 4$ & $57 \pm 5$ & $66 \pm 0.1$ & $73^{\mathrm{a}} \pm 5$ & $52 \pm 1$ & $71 \pm 0.6$ & $117^{a} \pm 3$ \\
\hline РCB 52 & $35 \pm 14$ & $36 \pm 6$ & $50^{a} \pm 5$ & $34 \pm 7$ & $50^{a} \pm 5$ & $60 \pm 11$ & $57^{\mathrm{a}} \pm 5$ & $47 \pm 3$ & $57 \pm 5$ & $71^{a} \pm 3$ & $58 \pm 5$ & $62 \pm 3$ & $71^{a} \pm 3$ & $54 \pm 3$ & $69 \pm 1$ & $99^{\mathrm{a}} \pm 3$ \\
\hline PCB 101 & $37 \pm 8$ & $35 \pm 5$ & $52^{\mathrm{a}} \pm 4$ & $34 \pm 3$ & $52 \pm 4$ & $56 \pm 12$ & $54^{\mathrm{a}} \pm 6$ & $47 \pm 1$ & $54 \pm 6$ & $68^{\mathrm{a}} \pm 4$ & $58 \pm 6$ & $65 \pm 1$ & $68^{\mathrm{a}} \pm 4$ & $54 \pm 3$ & $67 \pm 0.6$ & $107^{\mathrm{a}} \pm 1$ \\
\hline РCB 138 & $33 \pm 8$ & $36 \pm 7$ & $51^{\mathrm{a}} \pm 11$ & $32 \pm 5$ & $51 \pm 11$ & $48 \pm 15$ & $53^{\mathrm{a}} \pm 7$ & $47 \pm 0.3$ & $53 \pm 7$ & $70^{\mathrm{a}} \pm 0.8$ & $49 \pm 14$ & $62 \pm 0.1$ & $70^{\mathrm{a}} \pm 0.8$ & $57 \pm 2$ & $68 \pm 2$ & $99^{\mathrm{a}} \pm 0.1$ \\
\hline PCB 153 & $33 \pm 3$ & $35 \pm 19$ & $52^{\mathrm{a}} \pm 13$ & $33 \pm 6$ & $52 \pm 13$ & $49 \pm 13$ & $53 \pm 9$ & $46 \pm 6$ & $53 \pm 9$ & $69^{\mathrm{a}} \pm 0.9$ & $53 \pm 17$ & $60 \pm 0.4$ & $69^{\mathrm{a}} \pm 0.8$ & $58 \pm 0.3$ & $67 \pm 1$ & $99^{\mathrm{a}} \pm 0.8$ \\
\hline PCB 180 & $32 \pm 3$ & $36 \pm 4$ & $49^{a} \pm 8$ & $32 \pm 5$ & $49 \pm 8$ & $44 \pm 13$ & $50 \pm 10$ & $46 \pm 1$ & $50 \pm 1$ & $69^{a} \pm 4$ & $54 \pm 17$ & $59 \pm 2$ & $69^{a} \pm 4$ & $59 \pm 0.6$ & $65 \pm 2$ & $98^{\mathrm{a}} \pm 0.2$ \\
\hline
\end{tabular}

ACN: acetonitrile; ETA: ethyl acetate; ISO: isopropanol; HEX: hexane; ${ }^{a} p<0.05$ valued by $t$-test; PCB: polychlorinated biphenyls. 
Table 3. ANOVA statistics for regression including lack of fit-test for the solvent and matrix-matched calibration curves

\begin{tabular}{|c|c|c|c|c|c|c|}
\hline PCB & & Slope & Intercept & $\mathrm{R}^{2}$ & F-test & $p$ \\
\hline \multirow[t]{2}{*}{28} & hexane & 184.63 & -175.94 & 0.9949 & 0.198 & 0.664 \\
\hline & matrix & 215.89 & -137.63 & 0.9917 & & \\
\hline \multirow[t]{2}{*}{52} & hexane & 137.25 & -155.03 & 0.9989 & 0.020 & 0.890 \\
\hline & matrix & 146.97 & -229.79 & 0.9935 & & \\
\hline \multirow[t]{2}{*}{101} & hexane & 175.41 & -160.55 & 0.9978 & 0.039 & 0.846 \\
\hline & matrix & 185.99 & -85.59 & 0.9928 & & \\
\hline \multirow[t]{2}{*}{138} & hexane & 157.66 & -17.915 & 0.9957 & 0.082 & 0.780 \\
\hline & matrix & 227.49 & -217.24 & 0.9936 & & \\
\hline \multirow[t]{2}{*}{153} & hexane & 143.37 & -26.50 & 0.9977 & 0.217 & 0.649 \\
\hline & matrix & 178.13 & -198.91 & 0.9915 & & \\
\hline \multirow[t]{2}{*}{180} & hexane & 178.26 & -41.146 & 0.9982 & 0.244 & 0.630 \\
\hline & matrix & 226.57 & -400.62 & 0.9945 & & \\
\hline
\end{tabular}

PCB: polychlorinated biphenyls; F-test: variance ratio; $p$ : significance.

a considerable gain in signal-noise ratio compared with techniques such as soxhlet (Method 3540C) and ultrasound (3550C Method) ${ }^{16,17}$ (Figure S1).

\section{Validation}

Linearity, matrix effect and selectivity

After optimization, the method was validated by estimating the seven main figures of merit. The linearity of detector response was evaluated using seven concentration levels, including the limit of quantification, the maximum residue limit and the concentration used in the method optimization. Concentrations were equally spaced in the range evaluated. Replicates of each calibration point provided information on the inherent variability of the response measurements (pure error). The calibration data were obtained by linear regression and the determination coefficients $\left(R^{2}\right)$ were greater than 0.99 (Table 3 ). The lack of fit was not significant $(p>0.05)$ for the analytical curves prepared in the solvent and matrix extract, indicating the linearity of response in the range 4-60 $\mu \mathrm{g} \mathrm{L}^{-1}$ (Table 3).

Linearity was assessed by the ordinary least squares method (OLSM). The outliers were confirmed by the Jacknife residue test, with maximum exclusion of $22.2 \%$ in 21 replicates (Figure 2). The Ryan-Joiner test confirmed that the regression residuals were normally distributed, with correlation coefficients greater than the critical values and non-significant deviation from normality for the curves (Figure 3). Levene's test confirmed the homoscedasticity of residues, demonstrating the homogeneous distribution of residues. Independence of regression residuals with distribution of points without positive or negative trend was confirmed by the Durbin-Watson test (Figure 4). The results obtained after the tests confirmed the OLSM suitability to PCB 28 (Figures 2, 3 and 4) and similar results were found for the other biphenyls studied (data not shown). This complete system for linearity evaluation followed a procedure based on an acceptable and consistent statistics proposed by Souza and Junqueira. ${ }^{39}$

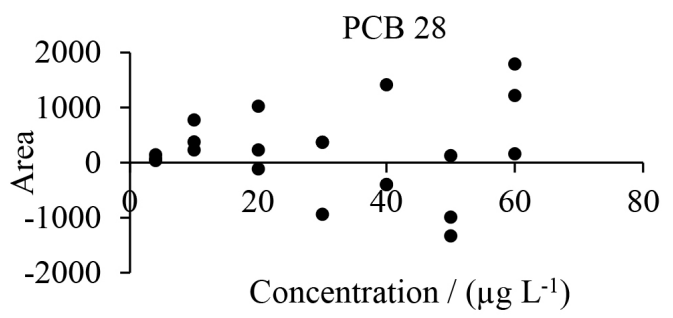

Figure 2. Residual plots for outlier diagnose by Jacknife standardized residuals test in matrix-matched calibration curve to PCB28.

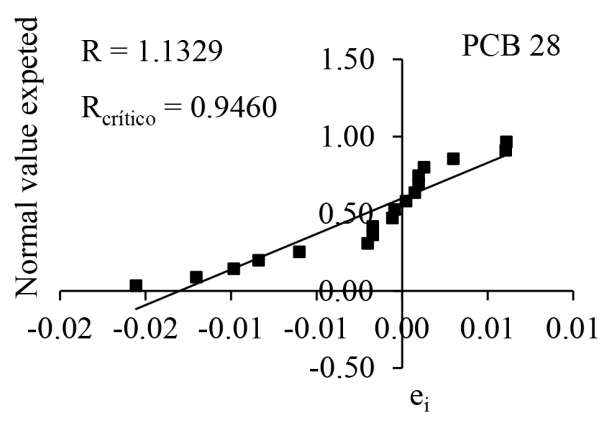

Figure 3. Normal QQ plots of residuals to PCB 28: $\mathrm{e}_{\mathrm{i}}$, residual and R, correlation coefficient of Ryan-Joiner test.

The matrix effect was detected in the GC-MS analysis for the six biphenyls, with significant differences in the chromatographic responses in hexane and in the sludge extract obtained after SLE-LTP $(p<0.05)$. The matrix effect 


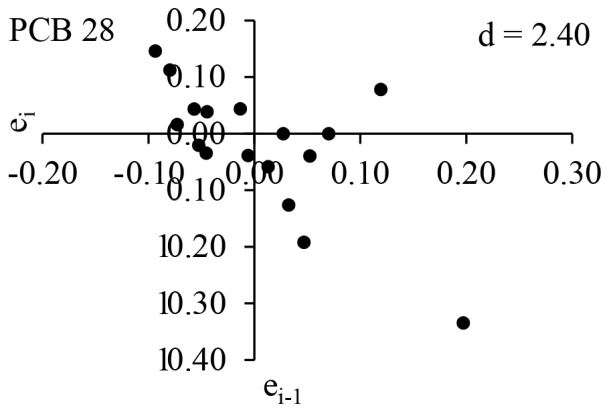

Figure 4. Plots of residuals autocorrelation to PCB28: $\mathrm{e}_{\mathrm{i}}$, residual and d, Durbin-Watson statistic.

caused an overestimation of analytical results, indicating a positive matrix effect. The increase of the chromatographic response in the analysis of the biphenyl standard solution at $50 \mu \mathrm{g} \mathrm{L} \mathrm{L}^{-1}$ was $75,72,110,151,150$ and $156 \%$ for PCBs 28 , $52,101,138,153$ and 180 , respectively. The area variation is associated with retention time of the six biphenyl since the longer the retention time, the greater the matrix effect. Similar results were found for pesticide analysis in tomato using SLE-LTP. ${ }^{26}$

The selectivity of the method was demonstrated by the absence of interferents in the retention time of the six biphenyls during the analyses of biphenyl-free sludge extracts (blank) (Figure 5).

\section{Detection and quantification limits}

The LOD achieved for the six biphenyls was $1.3 \mu \mathrm{L} \mathrm{L}^{-1}$ for the matrix extract and $3.3 \mu \mathrm{g} \mathrm{kg}^{-1}$ for the sludge sample. The
LOQ for the six biphenyls were $4.0 \mu \mathrm{g} \mathrm{kg}^{-1}$ and $10.0 \mu \mathrm{g} \mathrm{kg}^{-1}$ for the extract and the sludge sample, respectively. This value was less than the maximum residue limit established by Sewage Sludge Directive of the European Community ${ }^{40}$ that establishes limit for biphenyl $<800 \mu \mathrm{g} \mathrm{kg}^{-1}$.

\section{Accuracy and precision}

The accuracy evaluates the closeness of agreement between the measured values and the true value. Accuracy was assessed using recovery experiments at concentrations of $1 \times \mathrm{LQ}, 2 \times \mathrm{LQ}$ and $5 \times \mathrm{LQ}$, corresponding to 10,20 and $50 \mu \mathrm{g} \mathrm{kg}^{-1}$ of biphenyls in sewage sludge. The recovery percentages of the concentrations 10 and $50 \mu \mathrm{g} \mathrm{kg}^{-1}$ were in compliance with the recommendations of the European Commission ${ }^{40}$ which establish for concentrations $\geq 10 \mu \mathrm{g} \mathrm{kg}^{-1}$ recoveries between 80 and $110 \%$. These results are in accordance with International Union of Pure and Applied Chemistry (IUPAC) recommendations that suggest the range of 70 to $120 \% .{ }^{34}$ Precision tests evaluate the agreement between the results. Precision was evaluated under repeatability conditions in the concentration of $8 \mu \mathrm{g} \mathrm{L} \mathrm{L}^{-1}$ with satisfactory results, since RSD was less than $18 \%$ (Table 4 ).

\section{Application of the method}

Of the seven samples tested, PCB 52 was detected in June, July and August, and quantified in September $\left(60 \mu \mathrm{g} \mathrm{kg}^{-1}\right)$, October $\left(70 \mu \mathrm{g} \mathrm{kg}^{-1}\right)$ and November $\left(50 \mu \mathrm{g} \mathrm{kg}^{-1}\right)$. Similar concentrations of this biphenyl

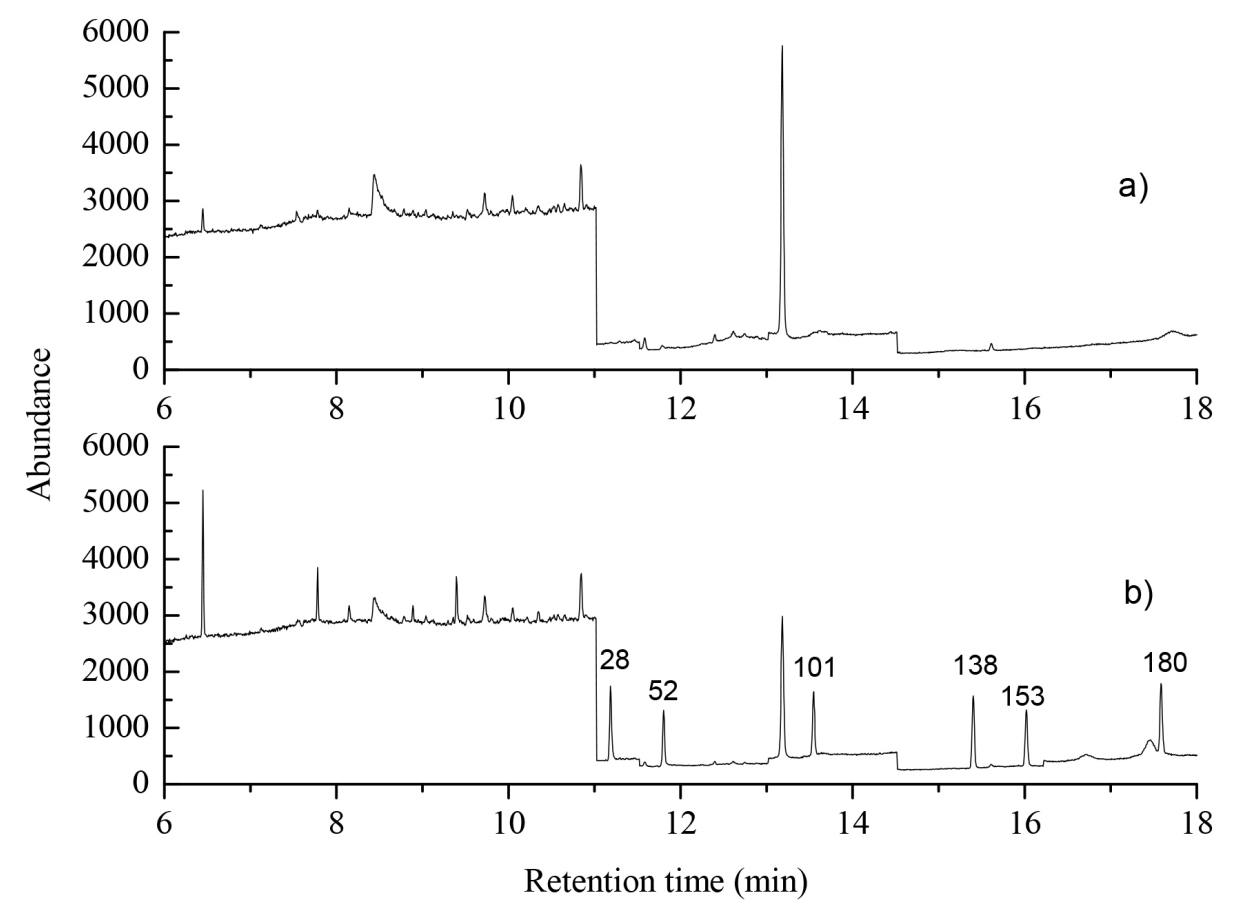

Figure 5. Chromatograms mode SIM of sewage sludge extract obtained after SLE-LTP: (a) blank; (b) samples spiked with PCB 28, 52, 101, 138, 153 and 180. 
Table 4. Mean recovery and relative standard deviation (RSD) for sewage sludge spiked at different level

\begin{tabular}{lcccccc}
\hline $\begin{array}{l}\text { Concentration / } \\
\left(\mu \mathrm{g} \mathrm{L}^{-1}\right)\end{array}$ & PCB 28 & PCB 52 & PCB 101 & PCB 138 & PCB 153 & PCB 180 \\
\cline { 2 - 7 } & $83 \pm 12$ & $82 \pm 5$ & $89 \pm 14$ & $86 \pm 11$ & $94 \pm 15$ & $82 \pm 16$ \\
$4^{\mathrm{a}}$ & $87 \pm 18$ & $89 \pm 5$ & $77 \pm 6$ & $61 \pm 12$ & $64 \pm 11$ & $66 \pm 13$ \\
$8^{\mathrm{b}}$ & $86 \pm 16$ & $85 \pm 11$ & $84 \pm 12$ & $88 \pm 7$ & $91 \pm 6$ & $84 \pm 1$ \\
$20^{\mathrm{a}}$ & &
\end{tabular}

${ }^{\mathrm{a}}$ Mean of three replicates; ${ }^{\mathrm{b}}$ mean of seven replicates; PCB: polychlorinated biphenyls.

were found in a study conducted in Turkey in the period 2009-2010..$^{41}$ The three samples had concentrations within the acceptable limit for biphenyls in sludge according to the European Community legislation $\left(<800 \mu \mathrm{g} \mathrm{kg}^{-1}\right) .^{40}$

\section{Conclusions}

Solid-liquid extraction with low temperature purification was optimized and validated for the determination of six PCBs in sewage sludge. The method is simple, easy to perform and has low consumption of solvents and samples. The technique is efficient with recovery rates higher than $80 \%$ in the limit of quantification for PCBs. PCB 52 was quantified in $40 \%$ of the analyzed sludge samples with values below the maximum acceptable limit established by the European Community legislation. The method is a viable alternative for monitoring PCBs in sewage sludge used for agricultural purposes.

\section{Supplementary Information}

Supplementary data are available free of charge at http://jbcs.sbq.org.br as PDF file.

\section{Acknowledgments}

Authors thank the National Council of Technological and Scientific Development (CNPq) and the foundation for Research Support of the State of Minas Gerais (FAPEMIG) (APQ-01786-13) for the financial support, and the Federal University of Minas Gerais (UFMG) for the infrastructure offered.

\section{References}

1. Passuello, A.; Cadiach, O.; Perez, Y.; Schuhmacher, M.; Environ. Int. 2010, 38, 1.

2. Zhang, L.; Xu, C.; Champagne, P.; Mabee, W.; Waste Manage. Res. 2014, 32, 586.

3. Leiva, C.; Ahumada, I.; Betsabet, S.; Richter, P.; Chemosphere 2010, 79, 273.
4. Rhind, S. M.; Kyle, C. E.; Kerr, C.; Osprey, M.; Zhang, Z. L.; Sci. Total Environ. 2011, 409, 3850.

5. Yager, T. J. B.; Furlong, E. T.; Kolpin, D. W.; Kinney, C. A.; Zaugg, S. D.; Burkhardt, M. R.; J. Am. Water Resour. Assoc. 2014, 50, 343.

6. Wen, B.; Li, L.; Zhang, H.; Mab, Y.; Shan, X.; Zhang, S.; Environ. Pollut. 2014, 184, 547.

7. Agency for Toxic Substances and Disease Registry (ATSDR); Toxicology Profile for Polychlorinated Biphenyls (BPCs), Department of Health and Human Services, Public Health Service: Atlanta, 2000.

8. El-Shahawi, M. S.; Hamza, A.; Bashammakh, A. S.; Al-Saggaf, W. T.; Talanta 2010, 80, 1587.

9. Adenugba, A.; Khan, S. A.; Taylor-Robinson, S. D.; Cox, I. J.; Toledano, M. B.; Thillainayagam, A. V.; Bansi, D. S.; Thomas, H. C.; Gibson, R. W.; Beck, A. J.; Chemosphere 2009, 76,841 .

10. Breivik, K.; Sweetman, A.; Pacyna, J. M.; Jones, K. C.; Sci. Total Environ. 2002, 290, 181.

11. Balasubramani, A.; Howell, N. L.; Rifai, H. S.; Sci. Total Environ. 2014, 473, 702.

12. Mohr, S.; Schwanz, T. G.; Wagner, R.; Soldatelli, L.; Costabeber, I. H.; Quim. Nova 2011, 34, 444.

13. Guo, L.; Zhang, B.; Xiao, K.; Zhang, Q.; Zheng, M.; J. Environ. Sci. 2009, 21, 468.

14. Rhind, S. M.; Kyle, C. E.; Ruffie, H.; Calmettes, E.; Osprey, M.; Zhang, Z. L.; Hamilton, D.; McKenzie, C.; Environ. Pollut. 2013, 181, 262.

15. Zabelina, O. N.; Saloutin, V. I.; Chupakhin, O. N.; J. Anal. Chem. 2010, 65, 1098.

16. Zuloaga, O.; Navarro, P.; Bizkarguenaga, E.; Iparraguirre A.; Vallejo, A.; Olivares, M.; Prieto, A.; Anal. Chim. Acta 2012, $736,7$.

17. United States Environmental Protection Agency (US EPA); Method 3540C, Test Methods for Evaluating Solid Waste Physical/Chemical Methods, SW-846 on CD-ROM; National Technical Information Service (NTIS), U.S. Department of Commerce: Springfield, USA, 1996.

18. United States Environmental Protection Agency (US EPA); Method 3550C, Test Methods for Evaluating Solid Waste Physical/Chemical Methods, SW-846 on CD-ROM; National 
Technical Information Service (NTIS), U.S. Department of Commerce: Springfield, USA, 2000.

19. Ilyas, M.; Sudaryanto, A.; Setiawan, I. E.; Riyadi, A. S.; Isobe, T.; Tanabe, S.; Chemosphere 2013, 93, 1500.

20. Bolzonella, D.; Fatone, F.; Pavan, P.; Cecchi, F.; Bioresour. Technol. 2010, 101, 9445.

21. Barbosa, E. S.; Evangelista, G. F.; Pimenta, E. M.; Silverio, F. O.; Pinho, G. P.; Quim. Nova 2014, 37, 404.

22. Pinho, G. P.; Silvério, F. O.; Evangelista, G. F.; Mesquita, L. V.; Barbosa, E. S.; J. Braz. Chem. Soc. 2014, 25, 1292.

23. McCulley, K. A.; McKinley, W. P.; J. - Assoc. Off. Anal. Chem. 1964, 47, 652.

24. Vieira, H. P.; Neves, A. A.; Queiroz, M. E. L. R.; Quim. Nova 2007, 30, 535 .

25. Goulart, S. M.; Queiroz, M. E. L. R.; Neves, A. A.; Queiroz, J. H.; Talanta 2008, 75, 1320.

26. Pinho, G. P.; Neves, A. A.; Queiroz, M. E. L. R.; Silvério, F. O.; Food Chem. 2010, 121, 251.

27. Magalhães, E. J.; Nascentes, C. C.; Augusti, R.; Queiroz, M. E. L. R.; Silva, J. C. C.; Afonso, R. J. C. F.; Am. J. Anal. Chem. 2012, 3, 118.

28. Goulart, S. M.; Alves, R. D.; Paula, W. X.; Queiroz, J. H.; Neves, A. A.; Queiroz, M. E. L. R.; J. Braz. Chem. Soc. 2012, 23, 1154.

29. Magalhães, E. J.; Queiroz, M. E. L. R.; Penido, M. L. O.; Paiva, M. A. R.; Teodoro, J. A. R.; Augusti, R.; Nascentes, C. C.; J. Chromatogr. A 2013, 1909, 15.
30. Morais, E. H. C.; Rodrigues, A. A. Z.; Queiroz, M. E. L. R.; Neves, A. A.; Morais, P. H. D.; Food Control 2014, 42, 9.

31. Costa, A. I. G.; Queiroz, M. E. L. R.; Neves, A. A.; Sousa, F. A.; Zambolim, L.; Food Chem. 2015, 181, 64.

32. Sousa, D. A.; Gonçalves, R. M.; Heleno, F. F.; Queiroz, M. E. L. R.; Marchi, M. R. R.; Microchem. J. 2014, 114, 266.

33. Pinho, G. P.; Neves, A. A.; Queiroz, M. E. L. R.; Silvério, F. O.; Food Control 2010, 21, 1307.

34. Thompson, M.; Ellison, S. L. R.; Wood, R.; Pure Appl. Chem. 2002, 74, 835 .

35. Hong, Q.; Wang, Y.; Luo, X.; Chen, S.; Chen, J.; Cai, M.; Mai, B.; Chemosphere 2012, 88, 1340.

36. Folch, I.; Vaquero, M. T.; Comellas, L.; Broto-Puing, F.; J. Chromatogr. A 1996, 719, 121.

37. Goulart, S. M.; Alves, R. D.; Neves, A. A.; Queiroz, J. H.; Assis, T. C.; Queiroz, M. E. L. R.; Anal. Chim. Acta 2010, 671, 41.

38. França, J. A.; Brandão, M.; Sodré, F. F.; Caldas, E. D.; Forensic Toxicol. 2015, 33, 93.

39. Souza, S. V. C.; Junqueira, R. G.; Anal. Chim. Acta 2005, 552, 25.

40. European Commission (EC); Council Directive 96/23/EC: Performance of Analytical Methods and the Interpretation of Results; Official Journal of the European Communities, 2002.

41. Ozcan, S.; Tor, A.; Mehmet, E. A.; Clean: Soil, Air, Water 2013, $41,411$.

Submitted: January 27, 2016

Published online: May 20, 2016 